\title{
A ATUAÇÃO DO SECRETÁRIO EXECUTIVO NO TERCEIRO SETOR NA CIDADE DE
} ARACAJU

THE ROLE OF THE EXECUTIVE SECRETARY IN THE THIRD SECTOR IN THE CITY OF ARACAJU

\section{Karen Almeida Pereira}

Graduanda em secretariado Executivo na Universidade Federal de Sergipe - UFS E-mail: karenalmeidap@ hotmail.com (Brasil)

\section{Manuela Ramos da Silva}

Mestre em Administração pela Universidade Federal da Bahia - UFBA

Professora do Curso de Secretariado Executivo da Universidade Federal de Sergipe - UFS

E-mail: mrs.gusmao@gmail.com (Brasil) 


\title{
A ATUAÇÃo DO SECRETÁRIO EXECUTIVO NO TERCEIRO SETOR NA CIDADE DE
} ARACAJU

\section{RESUMO}

A atuação do secretário executivo é indispensável para a gestão das organizações modernas. Essa afirmativa advém da atuação deste profissional diretamente com os gestores e executivos, pela multiplicidade de competências e da polivalência que ele possui, uma vez que este ator está apto a trabalhar em qualquer tipologia organizacional. Com o crescimento das organizações do terceiro setor no Brasil e também na cidade de Aracaju, o objetivo da pesquisa foi o de identificar quais as formas de atuação do secretário e quais as competências pertinentes desse profissional para trabalhar nessas instituições que possuem características peculiares na sua gestão. Para subsídio da pesquisa discutiu-se sobre terceiro setor e as características das organizações inseridas neste campo, a evolução da carreira do secretário, considerando a sua atuação no mercado de trabalho; e as competências a serem desenvolvidas. Dessa forma, identificaram-se, na cidade de Aracaju, organizações do terceiro setor que possuem uma gestão fragilizada devido, principalmente, à falta de recursos, à dependência financeira de outros órgãos e à ausência de mão de obra qualificada. No que se refere ao perfil dos secretários, a maioria não possui formação específica, são polivalentes, porém não são inovadores. Quanto à rotina de trabalho deles, ela está dividida em atividades operacionais e estratégicas, tendo como principal atribuição o assessoramento.

Palavras-chave: Terceiro Setor; Secretário Executivo; Competências.

\section{THE ROLE OF THE EXECUTIVE SECRETARY IN THE THIRD SECTOR IN THE CITY OF ARACAJU}

\begin{abstract}
The performance of the executive secretary is indispensable to the management of modern organizations. This affirmative comes from the performance of this professional directly with managers and executives, through a multiplicity of competence and versatility that they have, since this professional is able to work in any organizational typology. With the growth of the third sector in Brazil and also in the city of Aracaju, the objective of this research was to identify the acting ways of the secretary and which are the pertinent competences of this professional to work in these institutions that have peculiar characteristics in its management. In this research the third sector is discussed and the characteristics inserted in this field, the evolution of the secretary career, considering their role in the work market; and the competences that must be developed. Thereby, it was identified, in the city of Aracaju, third sector organizations that have a fragile management mainly due to lack of resources, financial dependency on other institutions and lack of qualified workers. Considering the secretaries profile, most of them do not have specific formation, are polyvalent, though not innovative. As for their working routine, it is divided into operational and strategic activities, with assistance as its main attribution.
\end{abstract}

Keywords: Third Sector; Executive Secretary; Competences.

Revista de Gestão e Secretariado - GeSec, São Paulo, v. 5, n. 1, p 104-130, jan./abr. 2014. 


\section{INTRODUÇÃO}

Nesta pesquisa discutiram-se as possibilidades de atuação do secretário executivo no mercado de trabalho, diante da diversidade de tipologias organizacionais (governo, empresas e organizações sociais), de maneira geral, e especialmente a atuação deste profissional na gestão das organizações do terceiro setor, em particular, na cidade de Aracaju.

Para este trabalho, foi considerado relevante identificar o perfil do secretário nestas organizações, a sua rotina de trabalho e as competências inerentes à gestão dessas instituições, tendo em vista o crescimento do terceiro setor no Brasil e também no estado de Sergipe.

Como o terceiro setor possui especificidades na sua gestão, as organizações deste campo enfrentam dificuldades em se manterem no mercado, principalmente, devido à dependência financeira dos outros setores da economia e dos seus filiados (Falconer, 1999), a pesquisa pretendeu descrever para os futuros secretários tais especificidades, bem como identificar as possibilidades de atuação neste nicho do mercado de trabalho.

A pesquisa foi dividida em cinco seções, em que teve como subsídio o terceiro setor em geral e as peculiaridades dessas organizações no âmbito sergipano, o novo perfil do secretário executivo e a sua atuação no mercado de trabalho. A metodologia classificou-se como exploratória e descritiva, de caráter quantitativo, constituindo uma pesquisa de campo, em que foi utilizado como instrumento de coleta de dados um questionário cuja finalidade foi identificar o perfil do secretário e diferenciar o nível prático desses profissionais por meio de uma escala tipo Likert.

$\mathrm{Na}$ análise dos resultados foi apresentado o perfil dos secretários e das organizações em que eles trabalham, no terceiro setor aracajuano, junto com as competências exercidas no dia a dia desses profissionais. Assim, pretendeu-se com esta pesquisa nortear os futuros secretários a identificar as características desse setor, os conhecimentos, habilidades e atitudes inerentes à gestão dessas organizações.

\section{REFERENCIAL TEÓRICO}

\subsection{O TERCEIRO SETOR}

As organizações deparam-se com diferentes tipos de gestões. De acordo com França (2004), existem três formas de gestão organizacional: gestão empresarial, gestão pública e gestão social. As duas primeiras são constituídas pelo mercado e pelo Estado, respectivamente, enquanto a gestão Revista de Gestão e Secretariado - GeSec, São Paulo, v. 5, n. 1, p 104-130, jan./abr. 2014. 
social é proveniente de Organizações não Governamentais (ONGs), Organização da Sociedade Civil de Interesse Público (OSCIP), entidades filantrópicas, entre outras. Portanto, pertencem a esse grupo as instituições sem fins lucrativos e de caráter público.

O termo usado para referir-se às organizações não governamentais, de interesse público e não lucrativas, chama-se terceiro setor, uma vez que o primeiro setor é o Estado e o segundo é composto pela iniciativa privada (Falconer, 1999; Jordan, 1997). Logo, o terceiro setor configurase por um conjunto de ações sociais promovidas pela sociedade em prol do bem público. Isso acontece em decorrência das lacunas deixadas pelo Estado e pelo Mercado, quando estes não conseguem atender toda a população. Como a demanda pelos benefícios é grande e contínua, esses dois enclaves não conseguem suprir totalmente as necessidades do povo, como educação, saúde, esporte, cultura, dentre outros, de modo que faz com que sociedade civil se movimente e organize a fim de ajudar e suprir as demandas da sociedade (Silva, 2008).

Para que uma organização social exista, é preciso atender a quatro aspectos que a caracterizarão como membro do terceiro setor, que são: a função social, as atividades sem fins lucrativos, autogerenciamento e autonomia interna - as duas primeiras características diferenciam este setor dos demais (Oliveira, 2003; Falconer, 1999; Santos \& Barbosa, 2004). Mesmo que a organização venha a obter lucro por meio de serviços, ele deve ser aplicado na entidade, ou seja, a receita deve ser destinada para beneficiar e melhorar a própria organização, não podendo distribuir o dinheiro com a gerência ou sócios, uma vez que a função dessas instituições não é gerar lucros, mas sim gerar bens e serviços em prol do público-alvo (Silva, 2008). Dessa forma, faz com que essas organizações se tornem dependentes financeiramente ou do Estado, mercado, população, ou por seus filiados - o que, consequentemente, gera fragilidades e obstáculos para promoverem suas atividades, pois o fim não lucrativo resulta em sinônimo de recursos escassos para as instituições desse âmbito.

Entretanto, apesar das inúmeras dificuldades que as organizações sociais encontram para se manterem no mercado, o terceiro setor, de maneira geral, cresceu e conseguiu o reconhecimento da sociedade na década de 1980, quando este setor surge como mercado social. Isso se deve, na ótica de Naves (2005) como citado em Silva (2008) à eficiência das execuções das atividades das organizações sociais, com resultados satisfatórios e o impacto positivo que geram na vida das pessoas amparadas pelos seus serviços.

A partir do reconhecimento, do crescimento e da ascensão da atuação do terceiro setor iniciaram os estudos, principalmente a respeito de sua gestão. Falconer (1999, p.11) destaca que

Revista de Gestão e Secretariado - GeSec, São Paulo, v. 5, n. 1, p 104-130, jan./abr. 2014. 
atividades como "planejamento, gestão de projetos, marketing, finanças, auditoria, liderança, motivação - antes restritos apenas ao mundo empresarial ou à administração pública, tornam-se comuns entre as organizações do terceiro setor". Isto é, os conceitos de administração e as suas funções só eram desempenhadas pelo primeiro e segundo setor, tendo em vista a forma como as instituições sociais surgiram.

De início, tinham o perfil mais informal, em que pessoas se comoviam com os problemas e dificuldades de outras e voluntariavam-se a fim de ajudá-las. Mas à medida que essas empresas foram tendo maior proporção e multiplicando as suas atividades, precisaram se aperfeiçoar e assim “tornou-se indispensável a contratação de profissionais tecnicamente preparados e profissionalmente remunerados, para que se obtivessem qualificações específicas para o andamento dos projetos" (Silva, 2008, p. 21).

Mas não se pode definir um modelo único de gerenciamento adotado e/ou utilizado pelas organizações do terceiro setor diante de uma maior complexidade na administração dessas instituições, uma vez que cada uma tem a sua missão, o seu público-alvo e as suas atividades específicas (Falconer, 1999). Logo, a gestão das organizações sociais caracteriza-se como complexa e heterogênea. De acordo com a literatura, há particularidades, na gestão dessas instituições que se tornam características comuns a elas, como lembra Falconer (1999, p10), a realidade da gestão da maioria das organizações sociais brasileiras é caracterizada por um ciclo vicioso composto pela falta de profissionais capacitados, gerenciamento inadequado, recursos escassos e a insuficiência de resultados, o que constrói o perfil dessas entidades.

Contudo, para que as organizações sociais desempenhem suas atividades de forma hábil e assim permaneçam no mercado, é preciso uma gestão eficiente, com conceitos administrativos ativos. Só foi possível diagnosticar essa problemática na década de 1980, além da qualificação dos profissionais e principalmente, dos gestores. Embora a dependência financeira ainda seja uma característica pertinente a essas organizações, apesar de muitas se destacarem por sua criatividade em captar recursos (Oliveira, 2003).

Embora, mesmo com crescimento das organizações sociais, ainda há instituições que encontram barreiras para se manterem no mercado, seja por falta de doações ou de parcerias concretas, ou pela falta de mão de obra qualificada. Não obstante, inserem-se nesse contexto, as organizações sociais da cidade de Aracaju. Segundo pesquisa de Santos e Barbosa (2004, pp. 2-14), a organizações sociais aracajuanas são, em sua maioria, de pequeno porte e também encontram dificuldades para amparar suas atividades, em decorrência da falta de recursos para sustentá-las e promovê-las. Destacam ainda, que elas possuem uma "estrutura organizacional ineficiente". Para os autores, isto é efeito da irregularidade e da escassez de recursos financeiros que caracterizam essas instituições, assim como a desqualificação da maior parte dos seus gestores, em especial a falta de Revista de Gestão e Secretariado - GeSec, São Paulo, v. 5, n. 1, p 104-130, jan./abr. 2014. 
formação e de experiência para que eles conduzam de forma eficiente estas organizações. Na ótica dos autores, uma estrutura organizacional eficiente só será possível através da capacitação dos gestores assim como uma aliança estratégica com os outros setores da economia, a fim de ascender às atividades e o desempenho dessas organizações. Todavia, seria interessante a busca pela autonomia, adotando estratégias para a captação de recursos e assim, quebrar a instabilidade financeira que predomina em grande parte das instituições do terceiro setor na cidade de Aracaju.

Assim, diante das peculiaridades para gerenciar organizações desse setor esta pesquisa considera relevante a presença de um profissional de secretariado executivo, a fim de contribuir para a melhoria da gestão, uma vez que este profissional possui um perfil proativo e conhecimentos multidisciplinares capazes de atender as atividades relevantes aos novos modelos de gestão das organizações.

\subsection{O PROFISSIONAL DE SECRETARIADO EXECUTIVO}

A função do profissional de secretariado existe na sociedade desde a antiguidade, que teve como precursores os escribas, os quais trabalhavam diretamente com os reis e líderes (Sabino \& Rocha, 2004). Reconhecidos pelo seu domínio na escrita, a função dos secretários naquele primeiro momento consistia em registrar as realizações feitas por seus superiores, o que esboça a função de assessor, diante da proximidade que o secretário tinha com os seus líderes (Sabino \& Rocha, 2004). Já na Idade Média, as funções secretariais eram compostas pelas atividades de cópias e arquivamento (Albernaz, 2011, p. 141).

Nos anos de 1950, depois do advento das máquinas de escrever, o profissional de secretariado tinha como principais atividades a taquigrafia, datilografia, guarda de documentos e atendimento telefônico. A partir dos anos de 1980, o perfil do secretário passa a ser novamente modulado, devido à existência da formação específica e à sua atuação mais complexa nas organizações (Sála, 2008).

Atualmente este profissional trabalha com a "administração, com a organização do trabalho, comunicação e expressão, apoio logístico, coordenação, gerenciamento da informação, psicologia das relações interpessoais e faz o papel de agente facilitador entre o gestor e os subordinados" (Siqueira, 2011, p. 1). Ou seja, o secretário deixou de ser um agente passivo e executor de tarefas rotineiras para tornar-se um agente ativo e polivalente que viabiliza decisões, corrobora Veiga (2010). 
Essa evolução do profissional de secretariado, faz parte da mudança organizacional, decorrente do "processo de globalização, complexidade maior das arquiteturas organizacionais e das relações comerciais [...] levando em consideração que as organizações buscam mais flexibilidade e velocidade de resposta e enfrentamento de complexidade crescente", conforme descreve Dutra (2008). Dessa forma, muda o perfil dos profissionais, assim como do secretário, uma vez que as organizações, diante de uma nova realidade de mercado, passaram a notar a necessidade de pessoas com mais poder de autonomia, de iniciativa e de comprometimento conforme as tomadas de decisões foram se tornando mais descentralizadas.

As mudanças organizacionais e as novas exigências do mercado de trabalho impuseram também outras formas de atuação dos profissionais, inclusive do secretário, com isso a formação acadêmica do profissional de secretariado se desenvolveu para acompanhar essa dinâmica organizacional.

Diante disso, esboça-se o novo perfil do secretário executivo perante as novas exigências do mercado de trabalho como sendo flexível, bom administrador de tempo, líder, comprometido com a empresa, proativo, com autoconhecimento, eficaz, multifuncional, especializado, gestor de fluxo de informação, mediador de conflitos, além das habilidades técnicas eficientes e do domínio da línguamãe e também de pelo menos uma estrangeira. Assim, o novo secretário desempenha funções de assessor (assiste um chefe ou mais), gestor (administra informação, pessoas, desenvolve atividades e implementa trabalhos), consultor (através da sua visão generalista da empresa identifica pontos críticos e desenvolve estratégias para melhorá-los) e empreendedor (implementa novas atividades e programas que otimizam o seu trabalho e dos outros) (Albernaz, 2011; Sabino \& Rocha, 2004).

Ao adotar uma posição estratégica na empresa, tornando-se um elo entre os subordinados e o gestor, o secretário precisou aperfeiçoar as técnicas secretariais, informatizando-as, tendo em vista uma execução eficiente e de forma rápida, para que a maior parte do seu tempo fosse utilizada na realização de suas novas tarefas, as quais impõem maior complexidade, como já foram destacadas.

No tocante à legislação educacional, em particular Resolução n. 3/2005/Conselho Nacional de Educação (CNE) as competências e habilidades que as Instituições de Ensino Superior (IES) devem desenvolver no futuro profissional de secretariado, destacam-se:

I - capacidade de articulação de acordo com os níveis de competências fixadas pelas organizações;

II - visão generalista da organização e das peculiares relações hierárquicas e intersetoriais; III - exercício de funções gerenciais, com sólido domínio sobre planejamento, organização, controle e direção;

IV - utilização do raciocínio lógico, crítico e analítico, operando com valores e estabelecendo relações formais e causais entre fenômenos e situações organizacionais; V - habilidade de lidar com modelos inovadores de gestão;

VI - domínio dos recursos de expressão e de comunicação compatíveis com o exercício profissional, inclusive nos processos de negociação e nas comunicações interpessoais ou

Revista de Gestão e Secretariado - GeSec, São Paulo, v. 5, n. 1, p 104-130, jan./abr. 2014. 


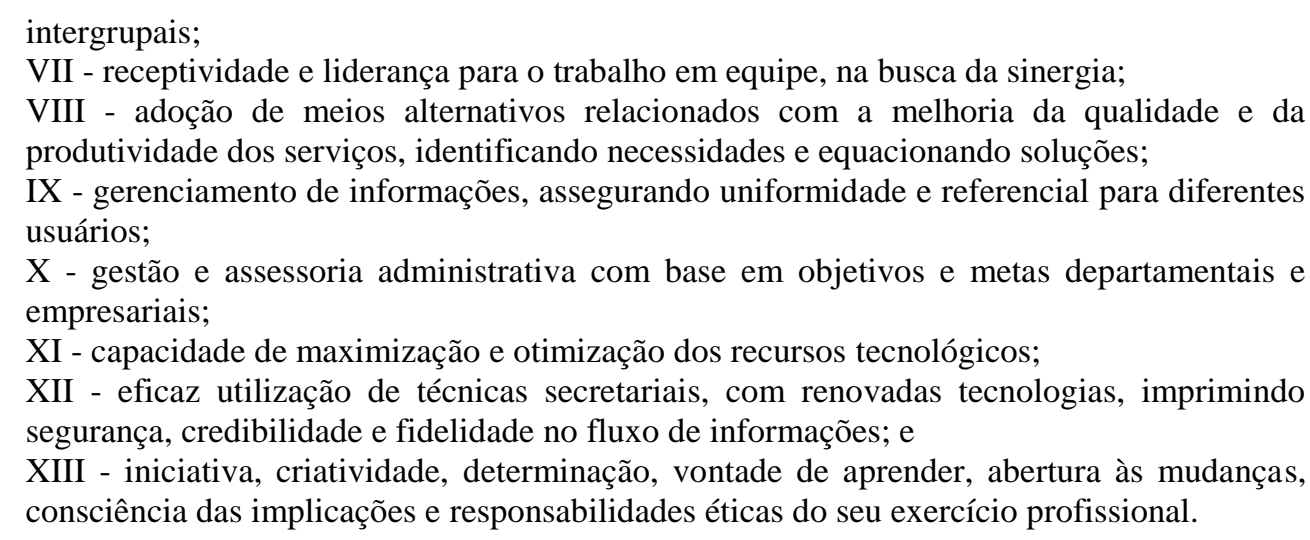

Contudo, para administrar tais atividades, houve também a necessidade de aprimoramento das atitudes do secretário em manifestar interesse para trabalhar em grupo, pois lida tanto com o cliente interno com o externo; demonstrar perfil de liderança, etiqueta profissional e ética, ou seja, a habilidade humana do secretário em saber se comportar e lidar com as pessoas é de extrema relevância ao considerar a posição que ele ocupa nas empresas. (Albernaz, 2011; Sabino \& Rocha, 2004).

Portanto, perante as competências destacadas do secretário, torná-lo um profissional apto para atuar em diversas áreas e setores da economia. Oliveira (2010, p. 33) salientou a relevância desse profissional no mercado de trabalho, uma vez que este ator "não executa apenas atividades rotineiras, mas assessora o executivo, logo, possui uma posição estratégica e faz parte do processo decisório da organização". Destaca-se, então, a presença imprescindível do secretário na gestão das organizações, de maneira geral, contribuindo de forma importante nos processos de tomada de decisão, no planejamento, nas funções gerenciais, nas resoluções de problemas, sobretudo, no assessoramento.

\subsection{MERCADO DE TRABALHO}

Segundo dados da Federação Nacional dos Secretários e Secretárias (Fenassec), o mercado de trabalho brasileiro é composto por mais de dois milhões de secretários, em pesquisa realizada em 1999. Porém, apenas setenta e sete mil deles têm o registro profissional. (Albernaz, 2011; Silva, 2012). Pode-se atribuir para essa diferença entre os números dos profissionais que são regularizados dos que não são, em virtude da maioria não requisitar da formação necessária, o que implica a ocupação dos cargos dos secretários. Tal questão pode ser justificada pela margem inferior de cursos superiores e técnicos na área capaz de suprir a demanda do mercado.

Revista de Gestão e Secretariado - GeSec, São Paulo, v. 5, n. 1, p 104-130, jan./abr. 2014. 
Existem, hoje no Brasil, 231 cursos superiores, dentre instituições públicas e privadas, reconhecidos na área de Secretariado Executivo (Albernaz, 2011). Na hipótese de que cada instituição egressa 50 alunos ao ano, média relativa de alunos por turma, teriam 11.550 profissionais qualificados anuais no mercado. Uma realidade bem abaixo do esperado, levando-se em conta que um curso superior leva, mais ou menos, quatros anos para formar um secretário.

Considera-se significativo o hiato entre o número de profissionais com a formação específica daqueles que não a possuem, sendo justificado pela demora do reconhecimento desse profissional e da lei que normatiza a profissão. Sabe-se que o profissional de secretariado surge na sociedade, lá atrás, na antiguidade. Porém, somente em 1969, surge, na Bahia, o primeiro curso superior de Secretariado no Brasil. Então, nos anos de 1970 começam realmente as mudanças que enaltecem e reconhecem a profissão de secretariado, devido à existência de um curso superior, que implicaria a qualificação necessária para ser um secretário; e o surgimento das associações da classe. Mas, somente nos anos de 1980 que a profissão ganha força ao ser amparada pela Lei 7.377, sancionada em 1985 e atualizada pela Lei n. 9.261 de 1996, que regulamenta a profissão, a qual reconhece o secretário como o profissional bacharelado em Secretariado Executivo e o técnico em secretariado, o profissional que possui o curso em Secretariado em nível de $2^{\circ}$ grau. Entretanto, apesar do crescimento que a classe obteve ao longo dos anos e o seu reconhecimento, o Secretariado ainda é uma profissão fragilizada em relação à ocupação regular no mercado pela ausência de um órgão fiscalizador na área, o que impossibilita a projeção de um panorama atualizado dos secretários que são regularizados daqueles atuantes na área (Albernaz, 2011; Andrade Júnior, 2011).

Limitando-se ao estado de Sergipe, segundo Andrade (2011, p. 22), em pesquisa acerca do cenário da profissão no mercado sergipano, há no estado "106 técnicos em Secretariado e 111 secretários executivos regularizados" para atenderem a "18.147 estabelecimentos, distribuídos nos setores da indústria, construção civil, comércio, serviços e agropecuária”, além das 104 secretarias públicas e federais, e das 75 prefeituras existentes no estado. O que acarreta em um déficit de 94,33\% de secretários habilitados, em projeção realizada pelo autor, considerando a contratação de pelo menos um secretário para cada empresa ou órgão. Segundo o autor "seria necessário um contingente de 1.959 profissionais regularizados".

Denota-se que o mercado de trabalho sergipano é composto por profissionais que exercem a função de secretário sem possuir a formação necessária para atuação. Isto é possível devido à não exigência no mercado em contratar profissionais de secretariado regularizados, tendo em vista que a maioria dos empresários não tem o conhecimento da legislação que regulamenta a profissão. Andrade (2011) afirmou que metade dos gestores entrevistados em sua pesquisa não tem essa informação, mesmo eles tendo ciência da existência do curso superior e técnico.

Revista de Gestão e Secretariado - GeSec, São Paulo, v. 5, n. 1, p 104-130, jan./abr. 2014. 
Ainda segundo o autor, as atividades aplicadas no cotidiano laboral dos secretários bacharelados no mercado de trabalho de Aracaju, através dos conhecimentos adquiridos na formação são aplicadas em "conhecimentos estratégicos, gestão de documentos, redação, marketing pessoal, conhecimentos humanos, línguas estrangeiras, gestão secretarial, técnicas secretariais, a habilidade de comunicação, planejamento e organização de eventos”. Desempenhos que corroboram com o entendimento dos gestores acerca do que é secretariar.

Verifica-se então, que o único curso superior em Secretariado existente na Universidade Federal de Sergipe (UFS) prepara o profissional para atuar no mercado, proporcionando os conhecimentos necessários que são aplicados nas organizações e os seus diversos enclaves. Porém, o que falta no Estado é o reconhecimento do secretário qualificado e a fiscalização. Considera-se que a exigência da formação específica para a contratação traria implicações e aumento na oferta por profissionais regularizados. Entretanto, o Estado só provém de uma instituição pública que tem curso superior em Secretariado, a UFS, cujo curso surgiu em 2007 e onde se formaram 22 profissionais até o término desta pesquisa, os quais não suprem a atual demanda de profissionais qualificados no mercado.

Acredita-se que esse cenário pode ser mudado a partir do engajamento e da adesão de esforços do "agente formador, regulador e empregador" (Andrade, 2011, p. 50). Porém, destaca-se a força de vontade de alguns profissionais regularizados e discentes em mudar esse panorama no Estado.

Quanto ao mercado de trabalho em organizações do terceiro setor, estas têm se mostrado promissoras de empregos, devido a seu crescimento e da diversidade de suas atividades, mesmo contendo algumas fragilidades. As instituições sociais têm, cada vez mais, contratado de profissionais com carteira assinada, que se comprometam mais com a instituição e que são necessários para assumirem atividades estratégicas, sendo que este setor não se focaliza apenas em atividades de caráter voluntário.

Dessa forma, o setor apresenta oportunidades de emprego para os profissionais e secretários atentos às especificidades que o terceiro setor contém e que sejam conscientes das dificuldades que as organizações sociais enfrentam para se manterem no mercado, contribuindo assim para uma melhor gestão.

Revista de Gestão e Secretariado - GeSec, São Paulo, v. 5, n. 1, p 104-130, jan./abr. 2014. 


\subsection{COMPETÊNCIA}

O conceito de competência tem sido debatido e estudado, nos últimos anos, tanto no âmbito acadêmico quanto no empresarial. E o debate é sempre nos mesmos interesses, seja a competência na forma de indivíduo (gestão de pessoas) ou na forma de organização (Dutra 2008, p. 9; Fleury \& Fleury, 2001, p.184). Essa repercussão perante o tema é decorrente ao novo modelo de gestão adotado pelas organizações. Com os processos de globalização, as organizações compreenderam a necessidade de contratação de profissionais mais autônomos, uma vez que o poder vem sendo descentralizado.

Segundo Fleury e Fleury (2001, pp.184-187), “competência é uma palavra do senso comum, utilizada para designar uma pessoa qualificada para realizar alguma coisa”, ou seja, quando o indivíduo executa o seu conjunto de capacidades que são: conhecimento, habilidade e atitude. Porém, na visão dos autores (p. 188), a noção de competência abrange mais que isso, uma vez que ela se associa ao saber agir, mobilizar recursos, integrar saberes múltiplos e complexos, saber aprender, saber engajar-se, assumir responsabilidades, ter visão estratégica, de modo que no final do processo agrega-se valor social para o indivíduo e valor econômico para a organização.

Por sua vez, Dutra (2008, pp. 28-31) destacou que esse conjunto do conhecimento, habilidade e atitude, que caracteriza a competência, não é sinal de que a pessoa, designada para a realização da tarefa, agregará valor para a organização. Ou seja, para o autor, o desempenho e a realização da tarefa só acrescentará valor para a empresa dependendo da forma como esse profissional se entregará para ela, de modo que mesmo com o afastamento do funcionário da organização, os valores deixados por ele permanecerão. E os valores agregados pelas empresas não só apenas econômicos, são também os de melhorias nos processos e introdução de tecnologias.

Dessa forma, definir que o conhecimento é a informação; habilidade é a técnica e; atitude é a determinação; apenas com a união desses três elementos que resultará num desempenho com competência. Um é dependente do outro. Porém, definir competência não é tão simples assim, uma vez que cada empresa enxerga a agregação de valor de uma forma. E conforme afirmou Dutra (2008, p. 33), competência “é um conceito em construção".

Para Sabino e Rocha (p. 94, 2004), o desenvolvimento da competência do secretário está associado aos saberes desse profissional em conhecer os problemas ao seu redor e o seu ambiente de trabalho, as tecnologias de informação, ser estratégico, gestor e observador. Ou seja, são esses fatores acoplados que condizem para um secretário competente. Verifica-se que o conjunto dos conhecimentos, das habilidades e das atitudes deste profissional refletem na sua competência, tendo em vista que este ator está completamente agregado à empresa, assumindo risco e atuando de forma eficaz.

Revista de Gestão e Secretariado - GeSec, São Paulo, v. 5, n. 1, p 104-130, jan./abr. 2014. 
Ainda segundo os autores (2004) a competência do secretário é desenvolvida no espaço técnico e social, como pode ser visto no Quadro 1.

Quadro 1 - Síntese das competências do secretário.

\begin{tabular}{|c|c|}
\hline COMPETÊNCIA TÉCNICA & COMPETÊNCIA SOCIAL \\
\hline Administração & Comunicação \\
\hline Organização & Responsabilidade \\
\hline Idiomas & Liderança \\
\hline Informática & Aperfeiçoamento \\
\hline
\end{tabular}

Fonte: Sabino \& Rocha, 2004.

Compreende-se a competência técnica como a capacidade do profissional de secretariado em administrar o ambiente de trabalho, planejar tarefas, saber organizar arquivos, reuniões, eventos; dominar um ou mais idiomas e ter bom conhecimento de informática. Já a sua competência social diz respeito a sua boa comunicação, a sua conduta responsável, postura ética, saber liderar um grupo e o seu conhecimento contínuo em aprimorar as suas técnicas.

Contudo, é a partir do conceito de competência e de seus principais elementos - o conhecimento, a habilidade e a atitude - que serão identificadas quais as competências inerentes ao secretário e que os norteiam na gestão social.

\section{MÉTODOS E TÉCNICA DE PESQUISA}

Esta pesquisa classifica-se como exploratória e descritiva, de caráter quantitativo, que teve como objetivo descrever a atuação do secretário executivo na gestão de organizações do terceiro setor na cidade de Aracaju.

Foi utilizado como instrumento de coleta de dados um questionário, o qual foi dividido em três partes. A primeira e segunda tinham por objetivo descrever sobre experiência profissional do

Revista de Gestão e Secretariado - GeSec, São Paulo, v. 5, n. 1, p 104-130, jan./abr. 2014. 
secretário e sobre a organização. A terceira parte foi do tipo Likert com quatro pontos, em que a escala tinha a finalidade de diferenciar o nível prático dos secretários. Tal instrumento foi construído a partir da análise das atribuições do secretário executivo, conforme rege a legislação, levando em consideração também as particularidades das organizações do terceiro setor. Assim, as competências foram divididas em três grupos, a saber: conhecimentos; habilidades; atitudes. Dessa forma, englobam-se não somente as questões técnicas, mas também as comportamentais, necessárias à execução de um determinado trabalho.

Os critérios de acessibilidade e aleatoriedade foram utilizados na seleção dos sujeitos. Informa-se que 48 organizações sociais foram contatadas por telefone das quais sete não tinham um secretário ou não se dispuseram em colaborar com a pesquisa. Foram encaminhados os questionários via e-mail e/ou aplicados para 41 secretários. Porém, só foram obtidas respostas de nove questionários - o equivalente a $22 \%$ do total de aproveitamento.

Ressalte-se uma limitação na pesquisa, quanto à identificação das organizações do terceiro setor na cidade de Aracaju. Não há um sítio que disponibilize uma lista com a relação dessas instituições. A busca pelas instituições foi realizada aleatoriamente, via internet ou por sugestão de pessoas que as conheciam. A outra limitação, sem dúvidas, foi a não resposta dos questionários, o que correspondeu a $78 \%$ do total dos enviados.

Com o auxílio de planilha eletrônica, os dados foram tabulados e cruzados para a aplicação de estatística descritiva e obteve-se como resposta a definição das frequências mais importantes.

\section{APRESENTAÇÃO E ANÁLISE DOS RESULTADOS}

\subsection{PERFIL DAS ORGANIZAÇÕES DO TERCEIRO SETOR DE ARACAJU}

Quanto ao perfil das organizações pesquisadas a maioria é caracterizada como de pequeno porte $(55,55 \%)$. Enquanto que $22,22 \%$ afirmaram trabalhar em organizações de médio porte e $22,22 \%$ atuam em instituições de grande porte.

Sobre o tempo em que os respondentes estão trabalhando na organização, $44,44 \%$ informaram que estão de um a dois anos na instituição; 22,22\% estão de dois a cinco anos; e $33,33 \%$ estão entre de oito a dez anos.

Com o índice de 44,44\% dos respondentes que trabalham de um a dois anos, comparando com a idade desses profissionais, corrobora o ínicio de carreira dos profissionais nessas instituições, o que se destaca então, o terceiro setor como um setor promissor para emprego, apesar de a maioria das organizações ser caracterizada como de pequeno porte.

Revista de Gestão e Secretariado - GeSec, São Paulo, v. 5, n. 1, p 104-130, jan./abr. 2014. 
Em relação à forma de como as organizações pesquisadas arrecadam dinheiro, 44,44\% dos respondentes as denominam como autossuficientes; 44,44\% dependem da ajuda financeira da população, seguida das que dependem das empresas privadas, também com 44,44\%; e apenas $11,11 \%$ dependem da ajuda do governo.

Nota-se que a maior dependência financeira das organizações do terceiro setor ainda é com os outros dois setores da economia e da população. Da amostra, algumas instituições alegaram depender de mais de um órgão acima mencionado. Contudo, apenas 44,44\% das organizações são autossuficientes, em especial são associações, sindicatos e instituições religiosas que se mantêm com a verba dos seus filiados.

A respeito das dificuldades que as organizações pesquisadas encontram para se manterem no mercado, os respondentes alegaram que um dos problemas é a deficiência de mão de obra qualificada, com 33,33\% das respostas; falta de recurso disponível, 22,22\%; falta de ajuda do Governo, também com 22,22\%; dependência financeira dos outros órgãos, $11,11 \%$; e 11,11\% desconhecem as dificuldades, pois alegam que a organização está bem conceituada no mercado.

Embora o fator não lucrativo seja uma característica para uma organização pertencer ao terceiro setor é este fator mesmo que gera uma barreira para que elas se mantenham no mercado; elas dependerão, em sua maioria, de organizações de outros setores, como foi visto nos dados anteriores.

Dificuldades apontadas como falta de recurso disponível, falta de ajuda do Governo e a dependência financeira dos outros órgãos mostram a fragilidade desse setor em relação à captação de recursos, com o maior percentual das respostas.

A deficiência de mão de obra qualificada $(33,33 \%)$ é apontada como dificuldade para se manterem no mercado por instituições da área sindical e religiosa, cujo problema é compreendido pelo fato de o nível de escolaridade dos profissionais não ser um fator de exigência nesses tipos de organizações. Destacam-se, principalmente, os secretários, pois apenas $11,11 \%$ da amostra têm a formação específica.

\subsection{PERFIL DOS SECRETÁRIOS DO TERCEIRO SETOR DE ARACAJU}

Esta seção apresenta o resultado da pesquisa realizada a nove profissionais que atuam como secretários em organizações que exercem atividades nas áreas de filantropia, religião, cultura e educação, inclusão social da criança e do adolescente, combate à violência, associação, sindicato e

Revista de Gestão e Secretariado - GeSec, São Paulo, v. 5, n. 1, p 104-130, jan./abr. 2014. 
assessoria técnica, na cidade de Aracaju - há instituição que atua em mais de uma área dessas citadas acima.

Quanto ao gênero, identificou-se que a maioria dos respondentes é do sexo feminino perfazendo 66,66\% dos respondentes - uma realidade ainda pertinente à área de Secretariado.

No que se refere à idade dos respondentes, 66,66 da amostra têm de 21 a 40 anos e apenas 33,33 acima dos 41 anos. Percebe-se que a maioria da amostra encontra-se em inicio de carreira, com faixa etária entre 21 a 40 anos, demonstrando que o mercado de trabalho das organizações sociais têm atraído os jovens profissionais, principalmente em virtude do seu crescimento na sociedade.

Quanto à formação escolar dos respondentes, 44,44\% têm o ensino médio; 33,33\% têm o ensino superior e apenas $22,22 \%$ com pós-graduação.

Nota-se que o maior percentual da amostra têm formação superior (55,55\%); quando somados o percentual dos que têm ensino superior com os respondentes pós-graduados, o que resulta em um setor com uma certa nível de profissionalização.

Sobre a área de conhecimento do curso de formação, dos 55,55\% dos respondentes que têm o ensino superior, 33,33\% não responderam a questão. Os demais declararam formação em Secretariado, com 11,11\%, e em Geografia Licenciatura, também com 11,11\%.

Constata-se que os respondentes que não informaram o curso de formação, que eles não são formados em Secretariado, pois quando perguntados sobre o conhecimento acerca da Lei 7.377 que regulamenta a profissão, eles afirmaram não ter o conhecimento da Lei $(22,22 \%)$ ou estavam sabendo naquele momento (22,22\%). Os que têm conhecimento acerca da referida lei correspondem a $55,55 \%$ das respostas.

Contudo, do total da amostra, somente $22,22 \%$ respondentes estão aptos para exercer a profissão legalmente, significando que $11,11 \%$ têm a formação específica e $11,11 \%$ estão amparados pela Lei 7.377, pois na data de sua vigência já estavam atuando há pelo menos oito anos (conforme Art. $3^{\circ}$ que assegura o direito do exercício da profissão daqueles que possuíam, pelo menos, cinco anos ininterruptos de atividades próprias de secretaria até a validade da lei).

Quanto ao tempo em que os profissionais entrevistados atuam na área de secretariado, $11,11 \%$ dos respondentes afirmaram atuar há quase um ano; 33,33\% atuam de um a dois anos; e $33,33 \%$ atuam de cinco a oito anos. Os que atuam há mais de 15 anos correspondem a 11,11\%, assim como os que atuam há mais de 30 anos, também com 11,11\% do resultado.

Como o maior percentual da amostra atua na área de secretariado entre um a oito anos, destaca-se, novamente, o início de carreira desses profissionais. Já os profissionais que atuam na função de secretário entre 5 a 30 anos destacaram que atuaram no mercado de trabalho, em sua

Revista de Gestão e Secretariado - GeSec, São Paulo, v. 5, n. 1, p 104-130, jan./abr. 2014. 
maior parte, em organizações do terceiro setor, indicando uma certa dedicação ao trabalho neste tipo de setor.

Com relação à estrutura organizacional, a fim de saber em qual nível hieráquico em que os respondentes estão inseridos, a maioria $(66,66 \%)$ respondeu atuar no nível operacional, enquanto $33,33 \%$ atuam no nível estratégico. Tal indicativo corrobora com a revisão teórica sobre a influência do secretário no processo decisório.

Do total da amostra dos respondentes que atuam no nível operacional (66,66\%), divide-se este percentual em 33,33\% dos que possuem o ensino médio com os 33,33\% que têm formação superior. Já no nível estratégico $11,11 \%$ responderam ter o ensino médio e 22,22\% têm ensino superior.

Percebe-se que, no caso das organizações do terceiro setor, não há uma exigência de escolaridade para atuar no nível hierárquico mais alto, mesmo o resultado mostrando que a maioria dos secretários que atuam no nível estratégico têm o ensino superior. Ou seja, observa-se uma inconsistência entre formação exigida aos profissionais nessas instituições e o nível hierárquico que atuam.

Ao atuar no nível estratégico de uma organização as funções do profissional são de identificar a missão, planejar tarefas e direcionar a empresa para o melhor caminho a fim de progredi-las, de modo que se vão criando estratégias, a longo prazo, para firmar clientes e driblar a concorrência. Já ao atuar no nível operacional, o profissional realiza as atividades rotineiras do dia a dia que foram preestabelecidas pelo nível estratégico e que oferecem suporte para alcançar as metas e objetivos da empresa.

A atuação nos diversos níveis hierárquicos de uma organização reforça a polivalência e a multifuncionalidade do secretário, uma vez que deve estar preparado para tais funções de acordo com a sua formação acadêmica.

Os setores de atuação em que os entrevistados trabalham são: 66,66\% dos profissionais de secretariado estão inseridos no setor administrativo; 44,44\% atuam no setor financeiro; $22,22 \%$ no setor de recursos humanos e $11,11 \%$ estão inseridos no setor social da organização.

Vale ressaltar que houve respostas em que os respondentes apontaram mais de um setor de atuação. Ou seja, mostra-se a polivalência desses profissionais ao atuarem em mais de um setor na organização. A partir de uma de suas atribuições, a assessoria, esta permite que ele assista o gestor de qualquer área, principalmente na área administrativa, uma vez que o secretário atua como um facilitador, resolvendo processsos burocráticos, administrando o ambiente e rotina do trabalho 
enquanto o gestor está focado no negócio da empresa. Daí a importância de o secretário estar ligado aos processos administrativos.

A jornada de trabalho dos respondentes indica que $11,11 \%$ trabalham $20 \mathrm{~h}$ semanais, seguido dos que trabalham $30 \mathrm{~h}$ semanais com $11,11 \%$; $66,66 \%$ trabalham $40 \mathrm{~h}$ semanais; $11,11 \%$ trabalham 44h semanais.

Sobre os salários dos respondentes, apenas $11,11 \%$ não recebem remuneração porque exercem o voluntariado; $11,11 \%$ recebem remuneração na faixa de $\mathrm{R} \$ 500,00$ a $\mathrm{R} \$ 800,00 ; 11,11 \%$ afirmaram receber de $\mathrm{R} \$ 801,00$ a $\mathrm{R} \$ 1.000,00$; os que recebem remuneração de $\mathrm{R} \$ 1.001,00$ a $\mathrm{R} \$$ $2.000,00$ correspondem a $22,22 \%$; e o equivalente a $44,44 \%$ do resultado recebem em torno de $\mathrm{R} \$$ $2.001,00$ a $\mathrm{R} \$ 3.000,00$.

Portanto, é possível inferir que a maioria dos secretários entrevistados recebem salários na faixa de $\mathrm{R} \$ 1.000,01$ a $\mathrm{R} \$ 3.000,00$, o equivalente a 66,66\% das respostas. Destaca-se uma média relevante da remuneração se for considerado o nível de escolaridade dos profissionais, uma vez que $44,44 \%$ dos respondentes têm apenas o ensino médio; e a instabilidade financeira das organizações do terceiro setor.

Outro dado interessante é que apenas 11,11\% fazem trabalho voluntário, com carga horária de 20h semanais; o que quebra um pouco a imagem de que só se trabalham voluntários - ou em maior quantidade - em organizações não governamentais.

Ainda sobre o perfil profissional, em particular, do diferencial dos profissionais no mercado de trabalho, a maioria da amostra aponta ter como diferencial a facilidade para trabalhar em grupo; em segundo lugar está o poder de liderança. Os entrevistados ainda indicaram alto grau de comunicação, seguido da especialização na área, além do espírito empreendedor e da organização e estratégia de captação de recursos, com os diferencias de menor importância, conforme gráfico abaixo

Gráfico 1 - Diferencial dos respondentes no mercado.

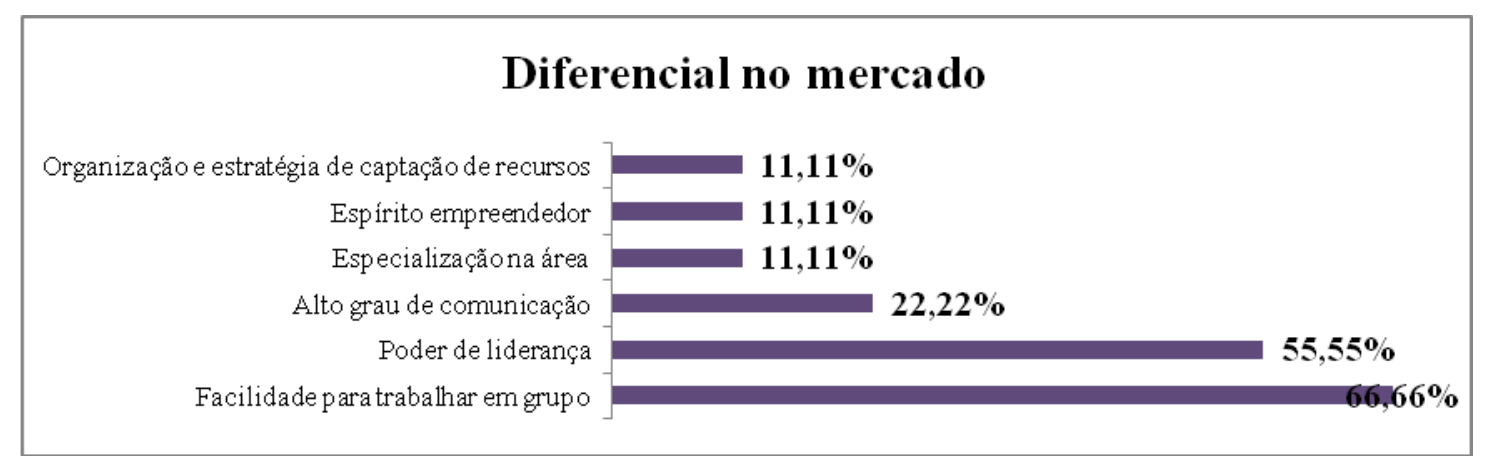

Fonte: pesquisa de campo.

Revista de Gestão e Secretariado - GeSec, São Paulo, v. 5, n. 1, p 104-130, jan./abr. 2014. 
Ressalta-se que nessa questão também houve mais de uma resposta mencionada. Observase, porém, uma contradição entre os profissionais que indicaram facilidade para trabalhar em grupo $(66,66 \%)$ e o alto grau de comunicação $(22,22 \%)$, uma vez que essas duas características se complementam. Se um profissional tem facilidade para trabalhar com outras pessoas, com certeza, ele terá e precisará de um bom grau de comunicação para interagir com elas, assim como o poder de liderança também está atrelado a essas duas características.

No que se refere ao espírito empreendedor, apenas 11,11\% afirmaram ter este diferencial, o que implica destacar que a maioria dos profissionais não estão atualizados na novas tendências e competências do profissional de secretariado.

Verifica-se que o diferencial desses profissionais não condiz com o novo perfil do secretário executivo o qual contempla todas as características citadas acima. Ou seja, só a partir da formação específica na área é que eles poderiam manifestar e desenvolver esses atributos tão importantes para a profissão, principalmente porque exercem a função de assessoria, cuja atividade requer todas essas qualidades para que ele possa atuar de modo competente e eficaz.

\subsection{ROTINA DE TRABALHO E AS COMPETÊNCIAS DO SECRETÁRIO DO TERCEIRO SETOR DE ARACAJU}

Abrindo o bloco das questões tipo Likert com escala de quatro pontos, buscou-se identificar quais atividades fazem parte da rotina do secretário do terceiro setor e quais as competências (conhecimentos, habilidades e atitudes) que eles consideram importantes para a realização das tarefas em seu dia a dia, considerando as atribuições inerentes do profissional de secretariado e as especificidades desses tipos de instituições.

Destaca-se que por meio desta análise será possível iniciar o levantamento sobre as possibilidades de atuação do secretário nesse setor e a sua rotina de trabalho e a sua contribuição para a gestão de tais organizações.

$\mathrm{Na}$ primeira questão, os secretários informaram as atribuições que são realizadas em seu cotidiano, considerando a frequência de realização delas numa escala entre sempre, frequentemente, às vezes ou nunca. Foram identificadas as técnicas secretariais e as atividades pertinentes à gestão que são desempenhadas pelos secretários com maior e menor frequência, como mostram os quadros de $1-5$.

Revista de Gestão e Secretariado - GeSec, São Paulo, v. 5, n. 1, p 104-130, jan./abr. 2014. 
Quadro 2- Técnicas secretariais executadas com maior frequência na rotina do secretário do terceiro setor.

\begin{tabular}{|c|c|}
\hline CLASSIFICAÇão & TÉCNICAS \\
\hline $1^{\circ}$ Lugar & Redação de correspondência ou documentos de rotina. \\
\hline $2^{\circ}$ Lugar & Organização e manutenção dos arquivos de secretaria. \\
\hline $3^{\circ}$ Lugar & Classificação, registro e distribuição de correspondência. \\
\hline $4^{\circ}$ Lugar & Coleta de informações para a consecução de objetivos e metas. \\
\hline
\end{tabular}

Fonte: Elaborado pelas autoras.

Identificaram-se outras técnicas que fazem parte do cotidiano dos secretários, porém o nível de frequência em que elas são realizadas é diferente de acordo com a posição do secretário na organização, uma vez que estão inseridos no nível operacional e no estratégico. Ou seja, a frequência da realização dessas técnicas é relacionada às tarefas pertinentes ao nível em que o profissional atua, como pode ser visto no Quadro 3.

Quadro 3- Outras técnicas secretariais que fazem parte da rotina do secretário do terceiro setor.

\begin{tabular}{|c|c|}
\hline CLASSIFICAÇÃO & TÉCNICAS \\
\hline $1^{\circ}$ lugar & $\begin{array}{l}\text { Redação de textos profissionais especializados; interpretação e sintetização de textos e } \\
\text { documentos. }\end{array}$ \\
\hline $2^{\circ}$ lugar & $\begin{array}{l}\text { Orientação da avaliação e seleção da correspondência para fins de encaminhamento à } \\
\text { chefia. }\end{array}$ \\
\hline $3^{\circ}$ lugar & Organização do ambiente de trabalho de quem assessora. \\
\hline $4^{\circ}$ lugar & $\begin{array}{l}\text { Execução de serviços típicos de escritório, tais como recepção, registro de compromissos, } \\
\text { informações e atendimento telefônico; Registro e distribuição de expedientes e outras } \\
\text { tarefas correlatas. }\end{array}$ \\
\hline $5^{\circ}$ lugar & Execução de conhecimentos protocolares. \\
\hline $6^{\circ}$ lugar & Organização de reuniões; Eventos. \\
\hline $7^{\circ}$ lugar & Digitação de ditados, discursos, conferências, palestras de explanações. \\
\hline
\end{tabular}

Fonte: Elaborado pelas autoras.

Revista de Gestão e Secretariado - GeSec, São Paulo, v. 5, n. 1, p 104-130, jan./abr. 2014. 
Identificou-se durante a pesquisa que as técnicas mais realizadas no nível operacional são as de conhecimentos protocolares e os serviços típicos de escritório. Já no nível estratégico é mais comum a realização de técnicas tais como organização de eventos e reuniões e digitação de ditados e discursos em palestras e conferências. Ou seja, infere-se que há coerência nas atividades técnicas desses profissionais considerando os níveis administrativos em que eles estão atuando.

No questionário, a rotina do secretário foi dividida em atividades técnicas e de gestão, conforme descritas nos Quadros 4 e 5.

Quadro 4- Atribuições mais executadas pelo secretário na gestão das organizações do terceiro setor.

\begin{tabular}{|c|c|}
\hline CLASSIFICAÇÃo & ATRIBUIÇÕES \\
\hline $1^{\circ}$ lugar & Soluciona problemas. \\
\hline $2^{\circ}$ lugar & Assistência e assessoramento direto a gestor/presidente. \\
\hline $3^{\circ}$ lugar & Planejamento, organização e direção de serviços de secretaria. \\
\hline $4^{\circ}$ lugar & Gerencia informações. \\
\hline $5^{\circ}$ lugar & Tem participação nas tomadas de decisões. \\
\hline
\end{tabular}

Fonte: Elaborado pelas autoras.

Quanto às atividades relacionadas à gestão, identificou-se a sua execução com maior e menor frequência pelos secretários que atuam no nível operacional e no estratégico. Tendo em vista a função básica do secretário, a assessoria, ela permite a realização de tais atribuições independentemente do nível hierárquico, pois, ao assistir o gestor, o secretário passa a ter uma visão generalista da organização, o que implica sua participação direta ou indireta na gestão da empresa.

Revista de Gestão e Secretariado - GeSec, São Paulo, v. 5, n. 1, p 104-130, jan./abr. 2014. 
Quadro 5- Atribuições executadas com menor frequência pelo secretário na gestão das organizações do terceiro setor.

\begin{tabular}{|c|c|}
\hline CLASSIFICAÇÃO & ATRIBUIÇÕES \\
\hline $1^{\circ}$ lugar & Capta recursos para a instituição. \\
\hline $2^{\circ}$ lugar & Elabora ideias de marketing. \\
\hline $3^{\circ}$ lugar & Elabora projetos. \\
\hline $4^{\circ}$ lugar & Decide sobre questões não programadas e inéditas. \\
\hline $5^{\circ}$ lugar & Controla a receita da organização. \\
\hline $6^{\circ}$ lugar & Gerencia sistema de informação. \\
\hline $7^{\circ}$ lugar & Seleciona e treina voluntários. \\
\hline
\end{tabular}

Fonte: Elaborado pelas autoras.

No que diz respeito ao Quadro 5, ressalta-se que essas atividades são realizadas com mais ênfase pelos secretários que atuam no nível estratégico dessas organizações.

Porém, destaca-se que a atividade de captação de recursos não é realizada pelas organizações que são autossuficientes (igreja, associações e sindicatos), e a seleção de voluntários só é realizada por uma destas.

Ainda sobre as atividades que constituem a rotina dos secretários do terceiro setor, Quadro 6, identificou-se que existem técnicas/atividades que quase não são realizadas no cotidiano destes profissionais, tornando-se atividades atípicas para eles.

Quadro 6- Técnicas/atividades quase não realizadas na rotina do secretário do terceiro setor.

\begin{tabular}{|c|c|}
\hline CLASSIFICAÇÃO & TÉCNICAS/ATIVIDADES \\
\hline $1^{\circ}$ lugar & Implementa novos programas de informática. \\
\hline $2^{\circ}$ lugar & $\begin{array}{l}\text { Redação de textos profissionais especializados, correspondências ou documentos em } \\
\text { idioma estrangeiro. }\end{array}$ \\
\hline $3^{\circ}$ lugar & Digitação de ditados, discursos, conferências, palestras de explanações em idioma \\
\hline
\end{tabular}

Revista de Gestão e Secretariado - GeSec, São Paulo, v. 5, n. 1, p 104-130, jan./abr. 2014. 


\begin{tabular}{|l|l|}
\hline & estrangeiro. \\
\hline $4^{\circ}$ lugar & Serve café. \\
\hline
\end{tabular}

Fonte: Elaborado pelas autoras.

Destaca-se que apenas um secretário, que atua em um sindicato, apontou que às vezes implementa novos programas de informática, o que se observa, então, é que esses profissionais não implementam novas atividades para otimizar o trabalho. Talvez isso possa ser justificado pela instabilidade financeira que as organizações enfrentam e devido aos recursos escassos pertinentes.

Quanto a uma atribuição pertinente ao secretário executivo, o domínio da escrita em idioma estrangeiro, esta só é realizada, às vezes, pelos secretários do nível estratégico que atuam em instituições religiosas e filantrópicas, tendo em vista que normalmente estas organizações têm parcerias com outros países.

Em relação a servir café, essa atividade foi questionada na pesquisa propositalmente a fim de saber se ainda há a imagem do secretário relacionada à prática deste serviço. Contudo, cinco profissionais marcaram que servem sim, às vezes, enquanto quatro apontaram que nunca serviram. Entretanto, identifica a eventualidade desta prática, o que não interfere na imagem nem na posição em que o secretário atua nesses tipos de organizações.

$\mathrm{Na}$ segunda questão desse bloco, os secretários apontaram as competências que eles consideram de relevância na execução das atribuições da rotina de trabalho num grau de muito importante, importante, pouco importante e nada importante. As respostas foram distribuídas em três grupos, a saber: conhecimentos, habilidades e atitudes (Quadros 7, 8 e 9) e enumeradas de acordo com as mais importantes:

Quadro 7 - Ranking dos conhecimentos mais importantes do secretário do terceiro setor.

\begin{tabular}{|c|l|}
\hline CLASSIFICAÇÃO & \multicolumn{1}{c|}{ CONHECIMENTOS } \\
\hline $1^{\circ}$ lugar & As funções de planejamento, organização, direção e controle de atividades administrativas. \\
\hline $2^{\circ}$ lugar & Microinformática. \\
\hline $3^{\circ}$ lugar & Técnicas de elaboração de agenda e conceitos básicos para o gerenciamento da informação. \\
\hline
\end{tabular}

Revista de Gestão e Secretariado - GeSec, São Paulo, v. 5, n. 1, p 104-130, jan./abr. 2014. 


\begin{tabular}{|l|l|}
\hline $4^{\circ}$ lugar & $\begin{array}{l}\text { Técnicas de planejamento, organização, execução e avaliação de eventos e métodos } \\
\text { arquivísticos. }\end{array}$ \\
\hline $5^{\circ}$ lugar & Técnicas de levantamento de dados. \\
\hline $6^{\circ}$ lugar & Cerimonial e protocolo. \\
\hline
\end{tabular}

Fonte: Elaborado pelas autoras.

Apenas os conhecimentos de organização de eventos, cerimonial e protocolo e levantamento de dados foram apontados, por dois secretários, como de pouca importância. Essas técnicas foram consideradas como as menos importantes tendo em vista que a maioria dos secretários não as praticam e também por haver profissionais específicos para a área de eventos e cerimonial. Mas, tendo em vista a função de assessoria exercida por eles, a técnica de levantamento de dados é um conhecimento importante a essa atribuição e também para o gerenciamento da informação.

Quadro 8 - Ranking das habilidades mais importantes do secretário do terceiro setor

\begin{tabular}{|c|c|}
\hline CLASSIFICAÇÃO & HABILIDADES \\
\hline $1^{\circ}$ lugar & Saber organizar o ambiente de trabalho. \\
\hline $2^{\circ}$ lugar & Ser capaz de utilizar as técnicas de redação oficial. \\
\hline $3^{\circ}$ lugar & Ser capaz de organizar reuniões administrativas. \\
\hline $4^{\circ}$ lugar & Ser capaz de organizar um arquivo. \\
\hline $5^{\circ}$ lugar & Saber organizar um evento. \\
\hline $6^{\circ}$ lugar & $\begin{array}{l}\text { Ser capaz de organizar e administrar um plano de comunicação inter e intradepartamental e } \\
\text { organizacional. }\end{array}$ \\
\hline $7^{\circ}$ lugar & Ser capaz de utilizar línguas estrangeiras no ambiente de trabalho. \\
\hline
\end{tabular}

Fonte: Elaborado pelas autoras.

Revista de Gestão e Secretariado - GeSec, São Paulo, v. 5, n. 1, p 104-130, jan./abr. 2014. 
Nessa questão apenas as duas primeiras habilidades foram apontadas como "muito importante" e “ importante", pois condizem com as atribuições mais executadas por eles. Quanto as demais, tiveram marcações como "pouco importantes", considerando a rotina dos secretários. A utilização da língua estrangeira foi apontada por dois secretários como uma habilidade de "nenhuma importância”, tendo em vista que não faz parte de suas atribuições. Entretanto, os outros secretários que não utilizam o idioma estrangeiro consideram-no "importante". Isto por que, mesmo que eles não usem outros idiomas no atual setor em que atuam, esta habilidade é relevante e faz parte das suas atribuições do secretário executivo. Não é por que esse profissional não a utiliza, no momento, que ela se torna irrelevante.

Quadro 9-Ranking das atitudes mais importantes do secretário do terceiro setor.

\begin{tabular}{|c|l|}
\hline CLASSIFICAÇÃo & \multicolumn{1}{c|}{ ATITUDES } \\
\hline $1^{\text {o } \text { lugar }}$ & $\begin{array}{l}\text { Demonstrar um bom relacionamento interpessoal, ética e postura profissional; desmonstrar } \\
\text { conhecimento dos processos organizacionais; ter boa comunicação. }\end{array}$ \\
\hline $2^{\text {o lugar }}$ & Manifestar interesse em trabalhar em equipe. \\
\hline $3^{\text {o lugar }}$ & Demonstrar etiqueta empresarial. \\
\hline $4^{\text {o } \text { lugar }}$ & Manifestar espírito empreendedor. \\
\hline $5^{\text {o } \text { lugar }}$ & Demonstrar perfil de liderança. \\
\hline
\end{tabular}

Fonte: Elaborado pelas autoras.

Infere-se que a atitude do secretário é a característica mais relevante, na ótica dos sercretários, pois quase todas foram apontadass como "muito importante" seguido de "importante" - o que demonstra que a habilidade humana é bastante relevante nesse setor. Apenas as atitudes de manifestar espírito empreendedor e demonstrar perfil de liderança, foram consideradas como de "pouca importância", por dois secretários. Ou seja, infere-se que ao julgar estas duas características intrínsecas a um secretário como não tão importantes, esses profissionais não têm ciência do novo perfil do secretário executivo, demonstrando assim a falta de conhecimento neste quesito.

Revista de Gestão e Secretariado - GeSec, São Paulo, v. 5, n. 1, p 104-130, jan./abr. 2014. 
Contudo, houve coerência na visão dos secretários ao analisarem as competências de acordo com o grau de importância de cada uma delas considerando suas rotinas de trabalho. Destaca-se que, mesmo considerando que ter boa comunicação é uma atitude de muita importância, eles não as consideram como um diferencial no mercado, conforme o Gráfico 5. Ou seja, há uma lacuna que enseja numa atitude necessária à profissão. Já a atitude de manifestar espírito empreendedor foi considerada de "pouca importância", comprovando, mais uma vez, que esse profissional não tem o perfil inovador nesse campo de atuação. Isso demonstra pouca contribuição na principal fragilidade das organizações do terceiro setor, a captação de recursos e sua sustentabilidade. Porém, mesmo com a demonstração dessas fragilidades dos secretários do terceiro setor e pela falta de formação específica destes, o perfil deles é bem próximo ao perfil esperado por um secretário executivo. Ou seja, talvez essas lacunas no perfil dos profissionais entrevistados, sejam em razão da não formação específica e ao não conhecimento das atribuições da profissão de secretário.

\section{CONSIDERAÇÕES FINAIS}

Observou-se que as organizações não governamentais aracajuanas caracterizam-se como sendo de pequeno porte e, principalmente, pela instabilidade financeira e pela ausência de mão de obra qualificada. Porém, mesmo diante de tais peculiaridades, nota-se que o setor é promissor para início de carreira do profissional de secretariado.

Quanto aos secretários desse setor, a maioria é do sexo feminino, possuem um perfil polivalente ao atuar em vários setores na organização e apenas um da amostra desta pesquisa tem formação em Secretariado. Identificou-se também que eles não possuem um perfil inovador, uma vez que não estão envolvidos em atividades relacionadas a questões tecnológicas e empreendedoras, bem como de liderança. Já no que se refere à faixa salarial desses profissionais, varia em torno de $\mathrm{R} \$ 1.000,00$ e R \$3.000,00, o que compreende em uma média salarial relevante considerando a falta de formação específica deles.

Sobre a rotina de trabalho, identificaram-se no cotidiano dos secretários, as atividades como o assessoramento, a gestão de documentos, redação de correspondência e documentos, solução de problemas e tomada de decisões. Quanto às competências que eles consideram importantes para a atuação no terceiro setor, destacam-se o conhecimento das atividades administrativas, microinformática, elaboração de agenda, organização do ambiente de trabalho e organização de reuniões e principalmente, a competência social.

Constatou-se que o profissional de secretariado que pretenda atuar nesta área tão promissora 
promoverem as suas atividades e assim permanecerem no mercado. Dessa forma, os secretários devem demonstrar o espírito empreendedor e inovador com o objetivo de elaborar ideias para a captação de recursos, o que contribuirá para uma gestão de qualidade e diferencial no mercado.

Porém, como a pesquisa identificou um perfil diferente desses profissionais nessas organizações, os futuros secretários terão um grande desafio ao desenvolverem essas atribuições.

Dessa forma, é possível destacar as possibilidades de atuação do secretário executivo em qualquer setor de uma organização social por meio da sua função de assessor, a qual lhe permite assistir qualquer gestor dos níveis hierárquicos, em virtude da sua polivalência, cuja característica é bastante importante para as instituições do terceiro setor. Diante do crescimento do mercado de trabalho deste âmbito e da diversificação das suas áreas de atuação, há a necessidade de contratação de profissionais com carteira assinada, com formação acadêmica e qualificação. Isso resulta que o profissional de secretariado qualificado contribuirá muito com novos tipos de gestões que estão sendo desenvolvidos nessa esfera.

Sugere-se para estudos futuros a realização do mapeamento das organizações do terceiro setor no estado de Sergipe.

\section{REFERÊNCIAS}

Albernaz, Cláudia Borges Lima (2011) O secretário executivo como gatekeeper da informação. Recuperado em 19 maio, 2012 de <http://repositorio.bce.unb.br/handle/10482/10089>.

Andrade, José Alberto Ferreira, Jr. (2011). Secretariado: Formação e mercado no estado de Sergipe [trabalho de conclusão de curso]. São Cristóvão: Universidade Federal de Sergipe, Curso de Secretariado Executivo.

Dutra, Joel Souza (2008). Competências: Conceitos e instrumentos para a gestão de pessoas na empresa moderna. São Paulo: Atlas.

Falconer, Andres Pablo (1999). A promessa do terceiro setor. Recuperado em 21 dez. 2011 de http://www.lasociedadcivil.org/docs/ciberteca/andres_falconer.pdf. 
França, Genauto de Carvalho, Filho (2004). Para um olhar epistemológico da administração: problematizando o seu objeto. In Santos, Reginaldo Souza (org.) A administração política como campo do conhecimento. São Paulo-Salvador: Edições Mandacaru.

Fleury, M. T. L. \& Fleury, A. (2001) Construindo o conceito de competência. Revista contemporânea de administração, [S. 1], 2001, pp. 183-196. Recuperado em 13 janeiro, 2012 de $<$ http://www.scielo.br/pdf/rac/v5nspe/v5nspea10.pdf. $>$.

Jordan, David Alberto Beker (1997). A carreira do administrador em organizações do terceiro $\begin{array}{llllll}\text { setor. } & \text { Recuperado } & \mathrm{em} & 8 & \text { janeiro, } & 2012\end{array}$ <http://3setor.com.br/downloads/acarreiradoadministrador.pdf.>.

Oliveira, Jamieli Barbosa de (2010). Competências do Secretário Executivo: uma reflexão sobre o processo de ensino-aprendizagem e o mercado de trabalho [trabalho de conclusão de curso]. São Cristóvão: Universidade Federal de Sergipe, Curso de Secretariado Executivo.

Oliveira, Rodrigo Nunes de. (2003) Análise da gestão de organizações sem fins lucrativos, estudo de caso. Recuperado em 30 novembro, 2011 de <.http://www.maternatura.org.br/servicos/biblioteca/An\%C3\%A1lise\%20da\%20Gest\%C3\%A3o $\% 20$ de $\% 20$ ONGs, \%20Estudo\%20de\%20Caso.pdf. A>

Sabino, Rosimeri Ferraz \& Rocha, Fabio Gomes (2004). Secretariado: do escriba ao Webwritter. Rio De Janeiro: Brasport.

Sála, Janeide Souza (2008). Guia de fontes de informação para secretários executivos. Recuperado em $30 \quad$ abril, 2012 de <http://www.fenassec.com.br/pdf/artigos_trabalhos_guia_secretariado_janeide.pdf.>.

Santos, André Gustavo Gomes de Almeida \& Barbosa, Jenny Dantas (2004). Organizações da Sociedade Civil De Aracaju: em busca de um modelo de gestão (XXVIII) - Encontro da Anpad - Associação Nacional de Pós-Graduação e Pesquisa em Administração Curitiba / PR 25 a 29 de setembro de 2004 . Anais Eletrônicos.

Silva, Ana Maria Netto (2012). Novo conceito do profissional secretário no contexto empresarial. Recuperado em 4 maio, 2012, de <http://www.fenassec.com.br/pdf/xiii_consec_palestras_Sintese_Ana_Maria_Netto_Silva.pdf

Silva, Vanusa Maria Queiroz da (2008). O raio-x do terceiro setor. Recuperado em 10 janeiro, 2012 de <http://bibliotecadigital.fgv.br/dspace/bitstream/handle/10438/2175/CPDOC2008VanusaMariaQ ueirozdaSilva.pdf? sequence $=1>$.

Siqueira, Márcia Cristina Moraes de (2011). Técnicas secretariais: reinvenção ou adequação? Recuperado em 12 dezembro, 2012 de http://fenassec.com.br..>.

Revista de Gestão e Secretariado - GeSec, São Paulo, v. 5, n. 1, p 104-130, jan./abr. 2014. 
Veiga, Denize Rachel (2010). Guia de Secretariado: técnicas e comportamento. (3a ed. rev. e atualizada). São Paulo: Érica.

Revista de Gestão e Secretariado - GeSec, São Paulo, v. 5, n. 1, p 104-130, jan./abr. 2014. 